\section{ANTONIO VIADA: REGENERACIONISMO, DEPORTE Y LENGUA ESPAÑOLA. LA INSTITUCIONALIZACIÓN DE LAS PRIMERAS VOCES DEL FÚTBOL EN ESPAÑA EN EL MANUAL DEL SPORT (1903)}

\author{
Antoni Nomdedeu-Rull \\ Universitat Rovira i Virgili \\ ORCID iD: https://orcid.org/0000-0003-2447-6954 \\ antonio.nomdedeu@urv.cat \\ Xavier Torrebadella-Flix \\ Universidad Autónoma de Barcelona \\ ORCID iD: https://orcid.org/0000-0002-1922-6785 \\ xtorreba@gmail.com
}

Cómo citar este artículo/Citation: Nomdedeu-Rull, A. y Torrebadella-Flix, X. (2018). Antonio Viada: regeneracionismo, deporte y lengua española. La institucionalización de las primeras voces del fútbol en España en el Manual del Sport (1903). Arbor, 194 (789): a470. https://doi.org/10.3989/ arbor.2018.789n3012

Recibido: 9 marzo 2017. Aceptado: 22 marzo 2018.

RESUMEN: El Manual del Sport de Antonio Viada publicado en España en 1903 se descubre como la primera obra técnica del deporte español que integra un capítulo dedicado al foot-ball, deporte hasta la fecha muy poco conocido en España. El objeto de estudio se centra en el análisis terminológico sobre el capítulo de foot-ball que incluye la presente obra, con el objetivo de recabar información que ayude a confeccionar el Diccionario Histórico de Términos del Fútbol en español que estamos elaborando.

PALABRAS CLAVE: Antonio Viada; Manual del Sport; fútbol; diccionario del fútbol; terminología del deporte.

\section{ANTONIO VIADA: REGENERATIONISM, SPORT AND THE SPANISH LANGUAGE. INSTITUTIONALISATION OF THE FIRST VOICES IN SPANISH FOOTBALL IN THE MANUAL DEL SPORT (1903)}

Copyright: (C) 2018 CSIC. Este es un artículo de acceso abierto distribuido bajo los términos de la licencia de uso y distribución Creative Commons Reconocimiento 4.0 Internacional (CC BY 4.0).

ABSTRACT: Antonio Viada's Manual del Sport, published in Spain in 1903, is the first technical work within Spanish sport that includes a chapter dedicated to foot-ball, a sport that was then little-known in Spain. This current study focuses on the terminological analysis of the chapter on football in order to obtain information of relevance for the compilation of the Historical Dictionary of Football Terms in Spanish that we are currently preparing.

KEYWORDS: Antonio Viada; Manual del Sport; football; dictionary of football; sports terminology. 


\section{INTRODUCCIÓN}

El fútbol es sin duda el deporte del que más líneas se han escrito. A partir de la popularidad que logró una vez terminada la I guerra mundial, no hay duda del protagonismo creciente que ha alcanzado como deporte universal. Es el deporte rey, el espectáculo de los espectáculos, generador de millones de textos de todo tipo. Como cita Paniagua (2010, p. 191), el fútbol proporciona, dentro del lenguaje periodístico deportivo, "el género rey", por los matices expresivos inherentes a su práctica competitiva.

Desde que el fútbol apareció en España en el último tercio del siglo XIX y tomó carta de naturaleza en los primeros años del siglo $\mathrm{XX}$, proporcionó los primeros textos de una bibliografía especializa (NomdedeuRull, 2015; Torrebadella-Flix y Nomdedeu-Rull, 2015). Fue también a principios de los años veinte del siglo pasado cuando en España este deporte también Ilamado balompié (Torrebadella-Flix y Nomdedeu-Rull, 2013) se erigió como el primer espectáculo de masas y generó una masiva bibliografía técnica y prensa especializada (Torrebadella-Flix y Nomdedeu-Rull, 2014; Torrebadella-Flix y Nomdedeu-Rull, 2015; TorrebadeIla-Flix y Nomdedeu-Rull, 2016).

El sport y la anglomanía desatada a partir de la restauración borbónica, junto al movimiento regeneracionista suscitado ante la crisis de 1898 , condujeron al entonces foot-ball a protagonizar la primera colonización de la lengua española de la historia contemporánea (Torrebadella-Flix, Olivera-Betrán y Bou, 2017). García-Candau (1996) trató esta cuestión en su día, y varias han sido las aportaciones que hasta el momento se han ocupado de este asunto (Aleixandre-Benavent, Agulló, Agulló, y Valderrama-Zurián, 2007; Castañón Rodríguez, 1993; Nomdedeu-Rull, 2015; NomdedeuRull, 2017; Pascual, 2012; Torrebadella-Flix y Nomdedeu-Rull, 2013; Torrebadella-Flix y Nomdedeu-Rull, 2015). Son muchas las palabras que tienen su origen en este lenguaje, al que llamamos deportivo, desde finales del siglo XIX y principios del XX. Los calcos -balompié- y los préstamos -fútbol- lingüísticos asoman por todas partes. En los primeros años de la Belle Époque, con el deporte ya como término propiamente definitorio para sustituir al sport (Olivera-Betrán y Torrebadella-Flix, 2015), surgió el interés por buscar un lenguaje adecuado (Vázquez Montalbán, Mercé Varela e Ibarz Melet, 1972). No obstante, estos comienzos no fueron fáciles puesto que existió una estrategia españolizadora del lenguaje deportivo anglosajón abanderada por quienes deseaban mantener una pureza de la lengua española y huir de cualquier barbarismo.
La construcción del lenguaje deportivo en el idioma tiene sus orígenes a partir de la penetración y divulgación de la lengua escrita. Principalmente es en la prensa deportiva o en las columnas deportivas de la prensa de noticias en donde se recogen las primeras referencias terminológicas del lenguaje deportivo (NomdedeuRull, 2017; Torrebadella-Flix y Olivera-Betrán, 2012). Estas voces, con el paso del tiempo, van a tener su aceptación en el lenguaje propio de cada deporte, y finalmente también muchas de ellas serán utilizadas en otros ámbitos no exclusivamente deportivos.

Puede afirmarse que, en el caso particular del fútbol, estas voces nuevas, en algunos casos anglicismos, fueron rápidamente incorporadas a los códigos terminológicos de los aficionados. Así, y en la medida en que estas nuevas palabras inundaban las crónicas futbolísticas de una incipiente prensa deportiva, aparecieron las discusiones lingüísticas y terminológicas, también reproducidas en las páginas de la prensa deportiva más relevante del momento (TorrebadellaFlix y Nomdedeu-Rull, 2013). En Los Deportes (18971910), la revista deportiva -publicada en Barcelonamás importante de España por entonces, es donde se advierten los primeros intentos por confeccionar y clarificar un marco terminológico definitorio. El principal artífice que promovió una estrategia españolizadora del lenguaje deportivo anglosajón fue el publicista Antonio Viada.

En este contexto, el objetivo de este estudio es dar cuenta de la novedad lingüística y de contenidos que supuso el Manual del Sport (1903) de Antonio Viada Viladesau (Mataró, 1862-Barcelona, 1914), obra publicada en Madrid en 1903, a partir del análisis de las primeras documentaciones léxicas de los vocablos del fútbol en español que se dan cita en sus páginas y de las primeras referencias a aspectos técnicos y tácticos del foot-ball que aparecieron en un manual (véanse las figuras 1 y 2). Sin duda alguna, esta obra fue una de las referencias más importantes para dar a conocer el juego y el reglamento a cuantos neófitos desearan conocerlo (Torrebadella-Flix y Nomdedeu-Rull, 2014). Asimismo, y teniendo en cuenta que este estudio se enmarca en el Diccionario Histórico de Términos del Fútbol (DHTF) que se está elaborando, no desatendemos algunos datos bio-bibliográficos del autor en relación con su obra objeto de estudio (Nomdedeu-Rull, 2015; Nomdedeu-Rull y Torrebadella-Flix, 2016).

La metodología seguida en este estudio ha consistido en la catalogación de los términos en torno al foot-ball que aparecen en la obra Manual del Sport y el contraste con la base de datos terminológica 
que sirve de base para la elaboración del DHTF, con el objeto de observar si entre los términos usados en el texto de Viada hay términos del fútbol documentados por primera vez en español. Es a partir del análisis terminológico descrito como proporcionamos un cuadro descriptivo de vocablos y una interpretación semiológica del lenguaje utilizado. Para ello en la metodología de análisis se han utilizado recursos y técnicas de análisis histórico en torno al tratamiento del léxico. Gracias a la digitalización de los textos fundamentales de la última década del siglo XIX, textos hallados en repositorios digitales diversos -Hemeroteca Digital de la Biblioteca Nacional de España y Biblioteca Virtual de la Prensa Histórica, entre otras-, se ha podido avanzar en las búsquedas y en la documentación de los términos de un modo mucho más rápido del que se hubiera procedido al carecer de las herramientas tecnológicas actuales. En último término, se ha procedido al vaciado léxico del Manual del Sport y a la exposición de las prime-

Figura 1. Antonio Viada a la edad de diez años en 1872

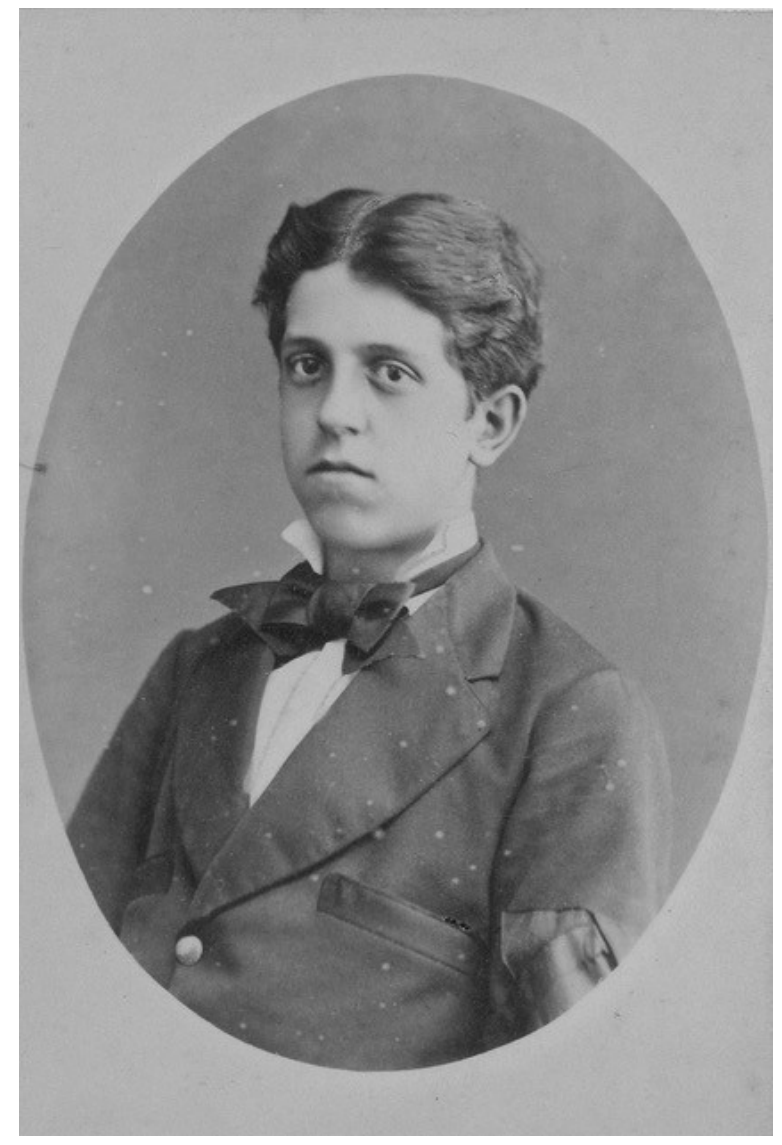

Fuente: Fotografía de Agustí Capmany Serra. Institut de Cultura de Barcelona. Museo Frederic Marès (Id. MFM S-21856). ras documentaciones léxicas que recoge, objetivo principal del presente estudio.

Así, pues, el estudio se presenta en un marco de contextualización del deporte, y en particular del fútbol, en la España de principios del siglo XX; seguimos con el conocimiento del autor en relación con su obra; $y$, finalmente, tratamos la terminología del fútbol en el Manual del Sport con el foco puesto en los términos que se documentan por primera vez en español en este manual. Por todo ello situamos la aportación del Manual del Sport de Antonio Viada en la confluencia del movimiento regeneracionista y de la llamada literatura del desastre, que también acompañó el devenir del deporte español de principios del siglo pasado (Torrebadella-Flix, 2014). Como se demuestra en este estudio, tanto el discurso de la obra como la práctica deportiva en sí misma tuvieron para el autor la intención de divulgar una obra de cultura física moderna y socialmente educativa.

Figura 2. "D. Antonio Viada. Constante mantenedor del sport, con incansable pluma y director de El Veloz Sport"

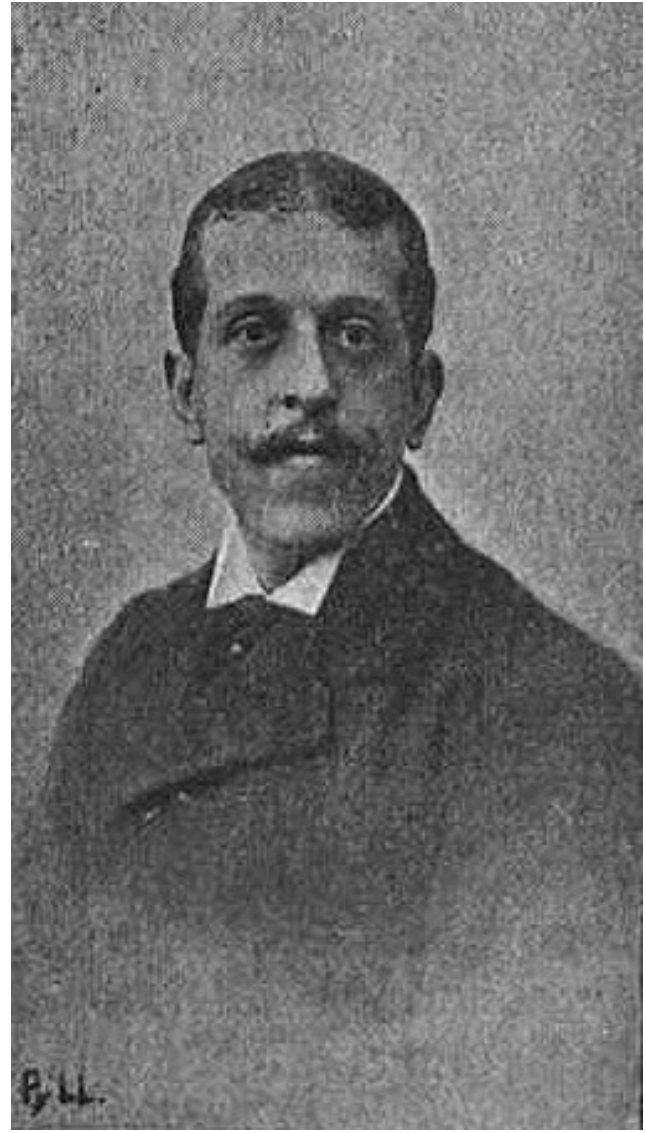

Fuente: La llustración Católica Española, 30 de enero de 1898 , p. 12. 


\section{CONTEXTUALIZACIÓN}

A finales del siglo XIX, el deporte tenía en España una elitista representación de asociaciones con una muy marcada representación burguesa (Torrebadella-Flix, Olivera-Betrán y Bou, 2015). La prensa deportiva de entonces es un ejemplo que testimonia el encanto que la pujante burguesía sentía por este nuevo estilo de ocio llamado sport (Torrebadella-Flix y Olivera-Betrán, 2013). Es en estos años cuando todavía el fútbol no había alcanzado un gran reconocimiento popular y en la prensa deportiva de la época se manifestaban algunas significativas opiniones, como la de Mariano de Cavia, que alertaban sobre el problema que podía suponer la invasiva oleada cultural anglosajona que se apreciaba en el sport (Torrebadella-Flix y Nomdedeu-Rull, 2013, p. 10).

A partir de comienzos del siglo XX, momento en el que las crónicas y las noticias del sport comenzaban a normalizarse en la incipiente prensa deportiva, Viada inició en 1902 la primera intervención de reafirmación lingüística de la lengua española en el deporte. Como hemos mencionado, las discusiones terminológicas ante la invasión de neologismos deportivos ocuparon un espacio destacado en las páginas de la revista Los Deportes. Puede decirse que el foot-ball fue el deporte con el que primero se levantó la polvareda después de la propaganda de Mariano de Cavia con la voz deporte y sus derivados (Olivera-Betrán y Torrebadella-Flix, 2015).

Aún, así, las discusiones para establecer un consenso terminológico de las voces del fútbol (y de las de otros sports) quedaron divididas en dos posiciones. Por un lado, había quienes defendían una traducción parcial de las voces inglesas; en cambio otros, entre ellos Narciso Masferrer, se posicionaban a favor de efectuar una transformación total y radical de las voces del foot-ball:

aconseja efectuar de una vez un cambio total y radical de todas las palabras del juego denominado de foot-ball, pues así como en Francia y en Alemania han efectuado traducciones parciales de algunas palabras, ó sea á medias, hagámoslo nosotros por completo dando muestra de mayor entusiasmo y decisión; pónganse de acuerdo todos los redactores de deportes de los periódicos locales; adopten los más apropiados, parecidos y lacónicos términos; publiquen los en tal forma constantemente y en breve tiempo quedarán adoptados y usados por el gran número de aficionados existentes hoy en la populosa ciudad Condal. (J. B., 1902, 9 de febrero $)^{1}$

Las discusiones sobre el lenguaje futbolístico fueron una constante a lo largo del primer cuarto del siglo pasado; y así se reflejó en la propia denominación del juego y sus diferentes voces propuestas: foot-ball, pila-pie, futbol, balompié... (Torrebadella-Flix y Nomdedeu-Rull, 2013). Es en este momento en el que se documenta por primera vez el préstamo futbol en un texto en español publicado en Los Deportes en la sección Intimidades firmada por Narciso Masferrer, forma que, aún sin tilde en esa época, acabará arraigando como denominación de este deporte hasta hoy. EI fútbol a la española ya se había puesto en marcha:

La afición ha cundido de tal modo, que todo el mundo juega ya á futbol... jes tan fácil cosa esa de lanzarse la pelota! Nuestra juventud, la que puede, acapara todos los balones de EI Siglo, y la que no, juega con piedras, con cajas de cartón, con lo que sea factible de empujarse con los pies é introducirse en el goal (Masferrer, 1903, 1 de marzo).

La aparición de la palabra futbol (sin tilde) en español se puede deber, a partir de algunas calas realizadas en la documentación textual de las primeras décadas del siglo XX, a la influencia de los periodistas catalanes en la divulgación del léxico del fútbol en estos primeros años del nuevo siglo, puesto que la forma futbol era ya de uso común en los textos en catalán referentes a este deporte: en La llustración catalana ya se documenta con regularidad desde 1903. Antonio Serra, escritor de la columna Notas de sport de La Vanguardia, empleó dicha voz en esta forma en español por primera vez el 17 de enero de 1903, aunque separada por un guion (fut-bol):

El presidente de la Asociación «foot-ball» («futbol») Clubs nos ha comunicado además, que dicho Tribunal-que se ha formado para entender en todos los asomos difíciles que pueden suscitarle en el juego en cuestión- ha organizado un concurso de (fut-bol) asociación exclusiva para segundos bandos de los Clubs constituidos en España (Serra, 1903, 17 de enero).

El año en el que aparece el Manual del Sport, en España el deporte contaba con una nutrida prensa deportiva fijada únicamente en Barcelona (Los Deportes y Vida Deportiva) y en Madrid (Heraldo Sport, Gran Vida, Revista del Sport, Arte y Sport).

Antonio Viada (1903) no se aventuró a indicar cuál fue la primera entidad futbolística o la primera zona de España en que se practicó el fútbol pero, por un lado, puso en este escenario el hecho de que las primeras asociaciones de este deporte estuvieron vinculadas a las colonias inglesas de Málaga, Mahón, Barcelona, Bilbao y otros puntos y, por el otro, identificó 
que Cataluña era la zona en la que este juego tenía más aceptación, con más de una veintena de clubes.

Si en Barcelona el fútbol se inició, claramente, a finales de 1899, en el caso de Madrid fue a principios de 1902 cuando se recogieron las primeras noticias de que este deporte iba progresivamente convirtiéndose en conocido. También la presencia del fútbol en el País Vasco, especialmente en Bilbao, sitúa esta región como la otra zona importante de la cantera futbolística del momento, es decir, la tercera potencia de fútbol en discordia. Las asociaciones y clubs regionales pronto movilizaron encuentros entre sus equipos y fue especialmente significativa la disputa oficial de la primera Copa del Rey, entonces competición considerada como el campeonato de España, que se disputó en Madrid. Así puede decirse que, organizativamente, el fútbol en aquel año solamente había cundido en Bilbao, Barcelona y Madrid, triángulo capital en la institucionalización fundacional del fútbol en España. En estos momentos, el fútbol estaba echando sus raíces en la población española y había salido de su reclusión colonial. Como citaba Gamper (1914), había quien menospreciaba el fútbol por eso de ser sport extranjero, otros lo veían antihigiénico, violento y bárbaro, un juego de los hijos de clase burguesa. Sin embargo, el fútbol pronto penetró en el entusiasmo de algunos defensores como Juan Gamper, Josep Elías y Alberto Serra en Barcelona, Juan Padrós y Ángel Berraondo en Madrid, y Ramón de Aras, Juan de Astorquia y Alejandro de la Sota en Bilbao (Polo del Barrio, 1993; Torrebadella-Flix, 2012; Turuzeta, 2012). Estos fueron los primeros apóstoles del fútbol en España y representaron el inicio de un proceso deportivo y de cultura anglosajona que ya estaba triunfando en muchas partes del mundo (Elías, 1901, 1 de marzo; Elías, 1903, 20 de septiembre). El fútbol se presentaba con una carga simbólica plenamente inmersa en el discurso regeneracionista del momento. Tanto es así que, desde otros círculos político-pedagógicos (vinculados a la Institución Libre de Enseñanza) impregnados por este ambiente, se concibió el fútbol como el mejor deporte que podía practicar la juventud española (Álvarez Santullano, 1903; Zulueta, 1903, 22 de septiembre).

Para conocer la visión del deporte a finales del siglo XIX y principios del siglo XX, hemos partido de unas notas de Antonio Viada, que llamó bosquejo históricocrítico, que revelan la situación española:

¿A qué es debida esta resistencia del público español á la vida sportiva? Porque hay que tener presente que el sport en nuestro país existe como excepción; no ha entrado en las costumbres. Todos los buenos sportmen saben esto (Viada, 1903, p. 18).
La visión de Antonio Viada ponía de relieve el abandono de la cultura física en España, que se encontraba a la cola de los avances modernos que las prácticas deportivas estaban protagonizando en Europa. Viada se compadecía de la indolencia y de la mezquindad de las retrasadas costumbres españolas.

En este sentido, el análisis en el campo de la cultura física y el deporte que trata Viada debería situarse a la altura de las brillantes aportaciones regeneracionistas del momento histórico (véase figura 3). Como hicieron los prominentes intelectuales de la generación del 98, Viada criticó la politiquería de los clanes oligárquicos y del caciquismo que, alejados de la regeneración que necesitaba España, no valoraban suficientemente las ventajas del ejercicio físico y de los juegos corporales, situación que ponía al país en receso respecto a los avances modernos. En todos los sentidos, el Manual del Sport es una obra que riega el regeneracionismo, el modernismo y el europeísmo.

En esta misión, Antonio Viada mencionó la excepcional contribución propagandística que, en manos de unos avanzados apóstoles, personificaba un momento de luchas cuyo objeto no era otro que conducir a las gentes y a los políticos hacia una nueva mentalidad que pusiese en tela de juicio las ventajas de civilización y de progreso que provenían del sport:

La prensa de gran empresa, es decir, la que se disputa el favor del público, dedicándose exclusivamente a servirle bien y trabajar por su ilustración y perfeccionamiento, prensa que sería la llamada á propagar las bienhechoras prácticas deportivas, esta prensa apenas existe en España. [...]

Todo el trabajo de propaganda deportiva debe reducirse en España a la de meritísimas y entusiastas asociaciones aisladas, y á la de no menos meritísimas publicaciones sin resonancia, que más tienen de apostolado que de negocio (Viada, 1903, pp. 19-20).

\section{ANTONIO VIADA Y EL MANUAL DEL SPORT}

En este apartado vamos a centrarnos en recuperar el valor que supuso la publicación del Manual del Sport a inicios del siglo XX. Entre 1899 y 1903, en Barcelona se impulsaron importantes efemérides de gran trascendencia en el ámbito del deporte, que especialmente tuvieron el Foot-ball Club Barcelona y la emblemática figura de Narciso Masferrer, amigo personal de Antonio Viada (Masferrer, 1911, 23 de noviembre), como principales mentores (Torrebadella-Flix, 2014). 
Figura 3. "Antonio Viada en su despacho"

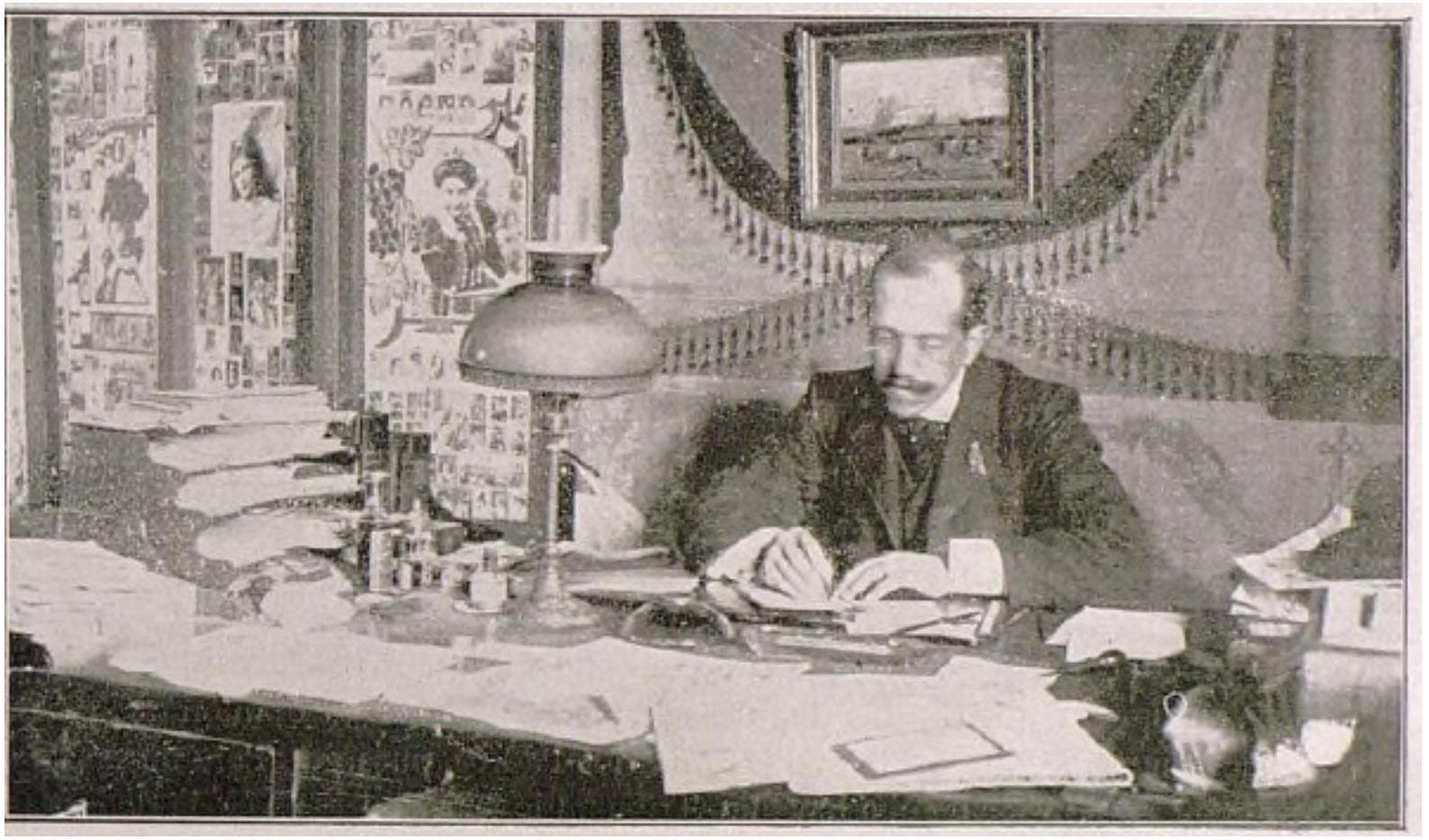

Fuente: Arte y Sport, 30 de marzo de 1904, p. 9.

Históricamente podemos recordar la figura de Antonio Viada por sus múltiples facetas periodísticas, pero debemos destacar que su Manual del Sport merece ser calificado como la primera gran obra del deporte español (Torrebadella-Flix y Olivera-Betrán, 2012) (véanse figuras 4 y 5). Su precio, 8 pesetas (tal como se publicitaba en el número 7 de la revista deportiva Gran Vida, del 1 de diciembre de 1903), era muy elevado en la época, pues equivalía a tres veces el sueldo de un obrero de principios del siglo XX. Véase el asiento descriptivo de la obra. En un total de 772 páginas, se compilaban las descripciones de 27 deportes:

Viada, Antonio:(Manuales Romoy Füssel) Manualdel Sport/por__ con un prólogo de Alejandro Saint-Aubin. Historia.-Generalidades.-Hípica.-Ciclismo.-Automóvil.Caza.- Pesca.- Esgrima.-Tiro.- Regatas.- Foot-ball.- Pelota vasca.- Tennis.- Cricket.- Base-ball.- Basket-ball.- Pushball.- Golfo.- Hockey.- Crosse.- Croquet.- Bochas.- Billar.Gimnasia.- Boxeo.- Lucha.- Skating.- Natación.- Pedestrismo, Ed. Adrian Romo, Madrid, 1903. XI-772 p.: il.; $17 \mathrm{~cm}$.

Su acogida en la prensa de la época fue notoria, pues se publicaron muchas reseñas de la obra. Des- tacamos un fragmento de la publicada en La Energía Eléctrica:

MANUAL DEL SPORT.- D. Antonio Viada, acaba publicar el libro cuyo título apuntamos con un prólogo originalísimo de Alejandro Saint-Aubin. La obra, que es indispensable, no sólo al sportman, sino al aficionado y á toda persona culta que desee marchar á la altura de los adelantos deportivos, delicioso oasis en el continuo batallar de la agitada vida moderna y vigoroso medio para mantener el equilibrio físico é intelectual de nuestra complicada máquina, después de la introducción reseña ligeramente la historia del sport, y en el capítulo de nociones generales que sigue al boceto histórico agrupa las diferentes clases de sports en un cuadro sinóptico, basado en sus analogías de objeto ó instrumento.

La exposición de los sports más en boga comprende diferentes capítulos, detallando con una claridad y sencillez admirables cuanto conviene conocer para imponerse, con sólo una lectura de agradable solaz, en el complicado mecanismo y ya extenso argot deportivo, pudiendo asegurar (al menos á mí me ha sucedido), que una vez cogido el libro, no se abandona su lectura hasta el final; quedando en la imaginación 
Figura 4. "Nuestros literatos"

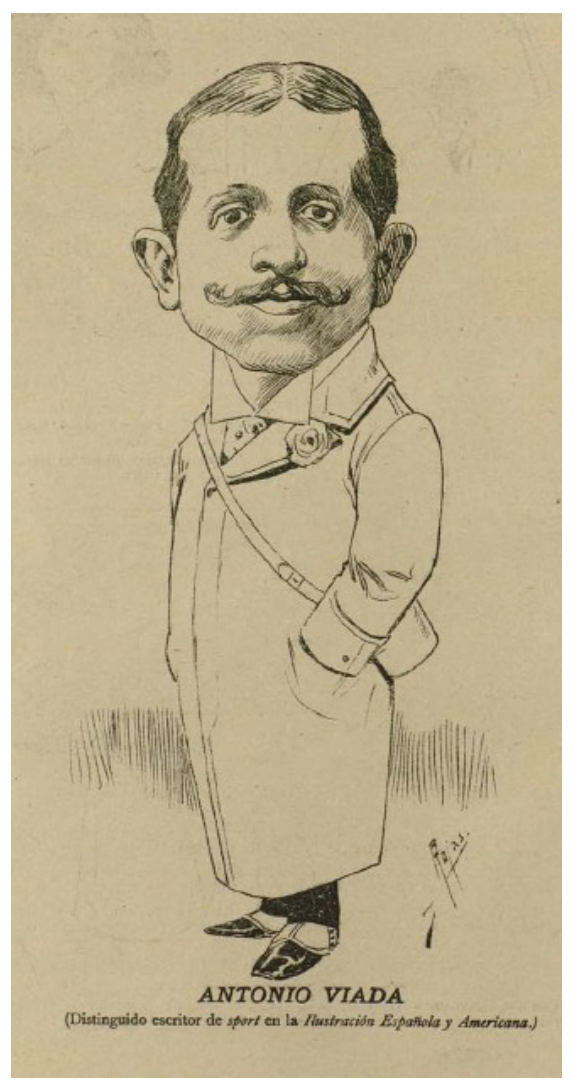

Fuente: El Cardo, 8 de mayo de 1900, p. 18.

impresión indeleble de multitud de ideas asimiladas sin esfuerzo y con el atractivo de la variedad (Bibliografía, 1903, 25 de junio).

Otra destacada reseña es la que se publicó en $L a$ Ilustración Española y Americana en la que se ensalzó el supuesto patriotismo y "españolismo" de Viada, del que él mismo huyó. Como se demuestra en las palabras siguientes, al final del artículo titulado "Sobre el vocabulario deportivo III", publicado en el número 16 de Los Deportes el 27 de abril de 1902, dejó clara su postura a este último respecto: «Permítame, además, me atreva á esperar de su buen deseo que contribuirá, por lo que toca á su coto cerrado, á la obra de españolización del idioma deportivo; tarea mucho más fácil que la tal vez no conveniente de la españolización de los españoles (?)» (Viada, 1902, 27 de abril). En esta última reseña, se refleja una vez más el discurso regeneracionista con el que nacía esta obra:

En la introducción de la obra, el Sr. Viada, estudiando la superioridad de la raza anglosajona sobre la latina, y apuntando la influencia decisiva de los sports
Figura 5. Manual del Sport (1903)

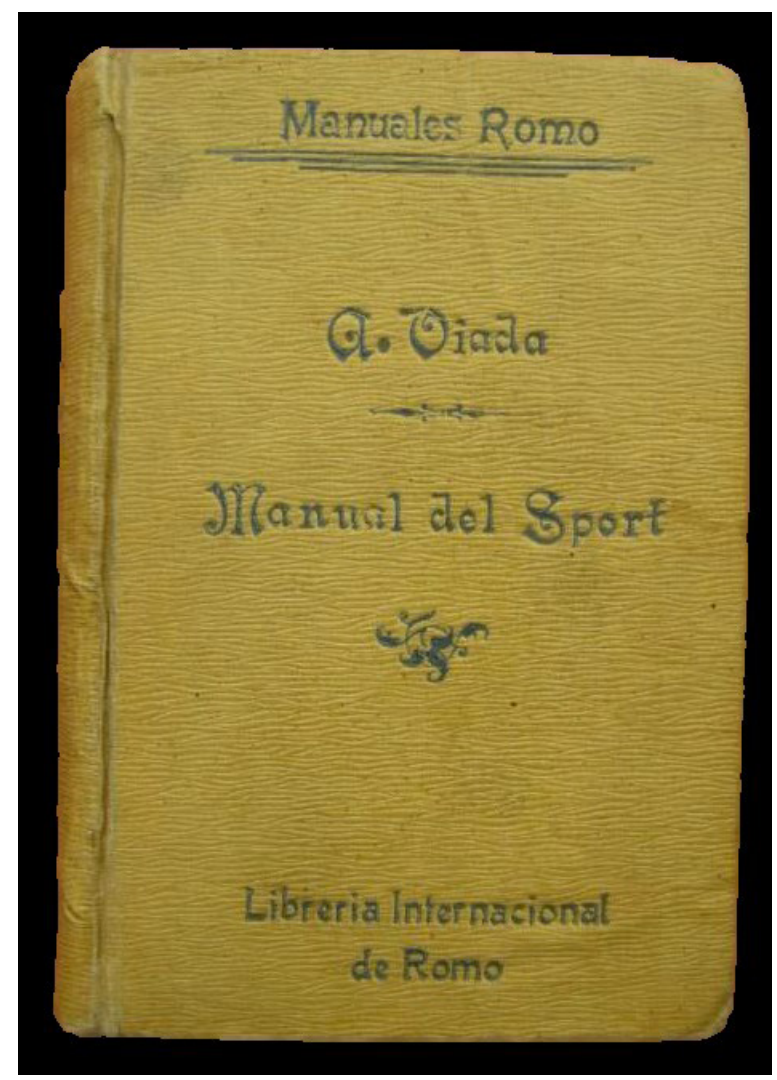

en tal superioridad, reproduce párrafos de los apasionados juicios emitidos por el barón de Hartcourt acerca de la última guerra hispano-americana, juicios altamente mortificantes para España. [...].

Todo el Manual es concienzuda y correcta exposición de la importancia capitalísima que para la nación entraña el cultivo del músculo, el mantenimiento de la vigorosidad corporal, el fortalecimiento de las energías físicas y la reconstitución de la salud social desequilibrada por exceso do trabajo cerebral. [...].

Ciclismo y automovilismo, esgrima y tiro, carreras hípicas y regatas, gimnasia y pelotarismo, billar y natación y otros muchos juegos encaminados á favorecer el "ejercicio físico al aire libre, que se practica por recreo y por estímulo", aparecen admirable y extensamente tratados por el Sr. Viada, que, con esta obra, presta un señalado servicio, no ya a los aficionados al sport, sino muy especialmente a nuestra raza, necesitada de traducir en hechos el consejo de Zola, "compensando el exceso de pluma con el exceso de gasto de calzado" (Manual del Sport 1903, 22 de agosto). 
También El Cardo se hizo eco de la noticia con un apunte que seguramente pertenecía a Narciso Masferrer:

Viada, mi querido compañero, el competentísimo escritor en materias deportivas, me acaba de favorecer con el envío de su Manual de Sport, que ha editado lujosamente la casa Romo y Füssel, de Madrid. Es el tal Manual un bouquin de 772 páginas, de modo que no he podido leerlo más que al vuelo, y claro está que no me puedo aventurar á dar mi opinión hasta bien conocidas todas las materias de que trata. Para entretener el tiempo y á guisa d'hors d'oeuvre, allá va un capítulo del Manual, en que Antonio Viada explica lo que es sport, y que ofrezco á mis lectores, convencido de que este platillo les sabrá á poco y acudirán prestos á la librería para darse el gustazo de un banquete... deportivo.

¡Que aproveche! (N. M., 1903, 15 de junio).

Acto seguido, el mismo Narciso Masferrer ofreció un capítulo del Manual del Sport de Antonio Viada titulado "Lo que es sport" en el que expuso el origen del término sport y derivados tales como sportman o sporting (Viada, 1903, 15 de junio).

Por lo tanto, la obra de Viada fue extensamente reconocida y, sin duda alguna, la valoración que hacía de ella Narciso Masferrer es la que más nos interesa, puesto que, a nuestro juicio, aporta reveladores datos del completo alcance que Viada deseaba ofrecer en las cuestiones terminológicas del deporte:

[...] un Manual del Sport, cuyo modesto libro encubre un tomo de cerca de 800 páginas, en que se tratan todos los deportes, y aún puedo añadir, que por conveniencia de los editores, suprimió Viada más de 200 páginas, entre las cuales contaban un vocabulario de más de 1.000 voces de sport, españolas y extranjeras. Este libro, a pesar de estas suspensiones, basta y sobra para acreditarlo entre nosotros todos como el primero entre los primeros, y por eso no podía dejar de figurar en el puesto de honor que hoy le asigna Arte y Sport en esta sección (Masferrer, 1904, 30 de marzo).

El Manual del Sport puede ser considerado como la primera aportación bibliográfica completa y moderna del deporte español. Torrebadella-Flix y OliveraBetrán (2012) la han clasificado como una de las cien obras deportivas más importantes de la historia del deporte en España. El libro trata con esmero y detalles aspectos históricos, técnicos y reglamentarios de numerosos deportes, algunos de los cuales apenas eran conocidos en España. En sí se trataba de una peque- ña, sencilla pero completa enciclopedia de deportes, la primera publicada en España. La dedicatoria tenía como protagonista:

[...] á las diversas entidades que en España trabajan por propagar el sport; á la Federación Gimnástica Española, en primera línea; al Tiro Nacional, á la Sociedad de Fomento de la Esgrima, a la Unión velocipédica española y á las asociaciones particulares de regatas, de polo, de foot-ball, de tennis, etc., etc.

Pero es poco libro este para ser dedicado. Es un modesto MANUAL del sportman, que se recomienda á la buena acogida de cuentos practican algún sport ó deseen practicarlos ó conocerlos (Viada, 1903, p. 8).

Viada introducía el sport a partir de los componentes comunes que estructuraban la práctica: campos de juego, instrumentos, pruebas, personal y reglamento. Asimismo, proporcionaba una clasificación "científica" a partir de la comprensión "lógica" de sus analogías según el objetivo o el instrumento utilizado: los deportes de carreras, que tienen como objeto la velocidad; los deportes de armas, que tienen por instrumento un arma; los deportes de balls (bolas o pelotas), que tienen por objeto este instrumento; y los deportes atléticos, que tienen por objeto los ejercicios gimnásticos o atléticos. Esta aportación puede considerarse como la primera clasificación sistemática española de los deportes.

La obra de Viada es la primera publicación española que ilustra y propaga a la perfección el estándar deportivo inglés. Asimismo, debe considerarse como una importante contribución al conocimiento del deporte en España, puesto que en aquella época el deporte era muy minoritario; incluso algunos de los deportes tratados tardaron bastantes años en practicarse, como en el caso del basket-ball, foot-ball, rugby o el skating-hockey. Puede afirmarse que, prácticamente, hasta la segunda década de siglo, el Manual del Sport fue el único referente del deporte moderno publicado con el que contaban los españoles.

El libro de Viada aparecía en la coyuntura de la crisis finisecular marcada por el desastre colonial de 1898. En esta época no existía prácticamente literatura deportiva, a excepción de unas pocas obras en torno al ciclismo (Torrebadella-Flix, 2011). El Manual del Sport fue la primera obra que se presentó alimentada ideológicamente por el discurso regeneracionista del momento (Torrebadella-Flix, 2014). Un análisis crítico sobre el discurso regeneracionista de la obra hace de ella que, en el ámbito del deporte y de la llamada regeneración física, se encuentre a la altura de obras 
críticas tan significativas como las que escribieron Joaquín Costa (1901) o Ricardo Macías (1899). Para validar esta afirmación, citamos unas palabras que el propio Antonio Viada escribió en esta obra:

Este anacronismo en el siglo XX y tratándose de un país europeo, más que á resistencia del público es debido á desconocimiento, como desconoce tantas cosas de la vida moderna. Por otra parte, del Estado, que en los países bien regidos es el tutor del país, no hay que esperar nada; pues no está siquiera definitivamente constituído, siendo la máxima política de todos los Gobiernos la vulgarísima de "vivir al día, y el que venga atrás que arree". Mientras tal barbaridad sea un axioma gubernamental español, que lo será hasta que los buenos españoles se decidan á intervenir en la gobernación del país, no será de extrañar, no ya que se desconozcan los beneficios del sport, sino que se desconozcan siquiera los servicios públicos bien organizados hoy en España prendidos con alfileres ó simples parodias de lo que son en Europa (Viada, 1903, pp. 18-19).

Asimismo, en el prólogo de la obra, Alejandro SaintAubin Bonnefont (1857-1916), corresponsal del Heraldo de Madrid en la guerra hispano-estadounidense y diputado por el partido liberal, dejó una imborrable huella histórica y del sentir regeneracionista del momento. Con estas palabras, que a continuación reproducimos, un lector mediante una carta anónima publicada en la prensa se hacía eco del Manual del Sport, coincidiendo con las opiniones de Saint-Aubin:

Tiene usted razón, no una, sino un millón de veces, querido amigo Alejandro. "Nuestros soldados, cuando salieron de España para combatir en los bosques y sabanas de Cuba, eran, grandes o chicos, hombres formados y robustecidos en las duras faenas del campo y de la fábrica, vigorizados en el tremendo sport del trabajo constante y del ejercicio muscular, para la conquista del pan. Cuando llegaron á las manos con los cowboys y con los rough-rider americanos, ya estaban los nuestros extenuados, rotos, hambrientos; reponiendo las fuerzas perdidas en la lucha por la fiebre, el paludismo, el calor sofocante y por la alimentación deplorable é insuficiente» (Manual del Sport, 1903, 10 de junio).

\section{EL LENGUAJE DEL FÚTBOL}

De los seis períodos en los que hemos divido la historia del léxico del fútbol entre 1890 y la actualidad -para lo cual hemos tenido en consideración factores históricos, textuales y futbolísticos, a partir, sobre todo, de las clasificaciones establecidas por los historiadores
Xavier Pujadas y Carles Santacana (2012), por un lado, y a partir también de las expuestas en Torrebadella-Flix y Olivera-Betrán (2013), en Torrebadella-Flix y Nomdedeu-Rull (2014), Torrebadella-Flix y Nomdedeu-Rull (2015) y Torrebadella-Flix y Nomdedeu-Rull (2016) y en Nomdedeu-Rull y Torrebadella-Flix (2016)-, el Manual del Sport de Viada se halla, desde el punto de vista textual, en la etapa que va de 1890 a 1913 y que hemos denominado Inicios de la prensa deportiva y creación de un espacio propio. Este período se establece porque es en 1890 cuando se documenta la primera crónica de un partido de fútbol (Recreativo de Huelva-Sevilla) y es en 1913 cuando se publica el libro Novísimo tratado de Foot-ball. Método práctico para jugar y apreciar la licitud y oportunidad de las jugadas, de Georges Graham, el primer libro monográfico de fútbol, además de que se crea la Real Federación Española de Fútbol. Esta datación obedece, pues, a razones textuales. Desde el punto de vista histórico, el manual estudiado pertenece a la etapa denominada etapa de gestación o regeneracionista, que va de 1900 a 1919. Esta etapa se caracterizó por la identificación del fútbol como signo elitista y burgués: este deporte se presentó entre connotaciones de moda y de regeneracionismo y se mostró como un excelente medio de educación física, principalmente en las escuelas privadas pertenecientes a las congregaciones religiosas. En estas dos primeras décadas se produjo un proceso de institucionalización del fútbol. Esta primera fase de gestación coincidió con el fin de la gran guerra en Europa y tuvo como colofón las demandas colectivas del deporte para organizar la participación en los Juegos Olímpicos de Amberes (Kuntz, 1919, 25 de diciembre; Reparaz, 1919, 15 de diciembre).

Desde el punto de vista léxico, como se ha expuesto en Nomdedeu-Rull (2014), no fue hasta 1902 cuando surgió la necesidad de reglamentar el juego del fútbol y su léxico (Nomdedeu-Rull, 2014), lo que se demuestra con la publicación del Reglamento de foot-ball de la Asociación de clubs de foot-ball de Barcelona en ese mismo año.

La presencia de los términos del fútbol comenzó a ser tan significativa en este periodo que a comienzos de siglo XX se produjeron dos fenómenos que demostraron el gran interés existente por informar sobre el juego del foot-ball. Por un lado, en 1902 se inició una etapa en la que varios redactores y periodistas de la época publicaron reflexiones sobre la adaptación de los términos futbolísticos en el marco de una estrategia españolizadora del lenguaje deportivo anglosajón (Nomdedeu-Rull, 2017). Por otro lado, se fundaron publicaciones periódicas que con el paso de los años 
se revelarían fundamentales. En 1902 apareció en Madrid el periódico Heraldo del Sport, dedicado prevalentemente al automovilismo y al fútbol, aunque también abordó cuestiones de, entre otros deportes, ciclismo, esgrima, yachting o hípica. Al año siguiente, en 1903, se fundó el periódico deportivo Gran vida (1903-1935), la Revista de Sport, el diario general ABC (1903-) y se publicó el Manual del Sport de Antonio Viada. Por lo tanto, nos hallamos en un periodo de recepción del léxico futbolístico, y concretamente en los textos periodísticos, en el que todavía no había surgido la preocupación por la denominación de las voces, si bien este interés estaba próximo, debido sobre todo al caudal de anglicismos que atestaría las páginas de las publicaciones de la época desde 1902. Imperaba la novedad del nuevo juego, lo que ocasionaba la aparición de noticias asociadas a él, como la constitución de nuevos clubes o la celebración de partidos.

Hasta 1903, pues, con las excepciones del Reglamento de foot-ball de la Asociación de clubs de Football de Barcelona y del Manual del Sport de Antonio Viada, las documentaciones léxicas del fútbol se hallan en periódicos de diverso género. En 1868 podemos documentar la primera referencia al fútbol, publicada en Valencia en El Panorama, Periódico ilustrado quincenal, el 30 de abril de $1868^{2}$, cinco años después de la creación de The Foot-ball Association en Londres (1863). Habrá que esperar a 1890 para encontrar la primera crónica de un partido de fútbol de la que tenemos conocimiento, publicada en La Provincia (Huelva) el 12 de marzo de 1890. A partir de 1890, la publicación de crónicas, y no solo de noticias breves, conllevó que aumentara el número de primeras documentaciones léxicas, esto es, de neologismos en la época. Desde este momento, comenzaron a aparecer noticias en la prensa de información general, sobre todo en La Vanguardia, lo que provocó un aumento, si bien lento, de términos documentados por primera vez (Nomdedeu-Rull, 2017).

\section{EL LENGUAJE DEL FÚTBOL EN EL MANUAL DEL SPORT}

Desde el punto de vista lingüístico, el Manual del Sport de Antonio Viada es un libro innovador y fundamental para poder explicar la historia del léxico del fútbol en español. Sin duda, forma parte del corpus lingüístico del fútbol español que sirve para esclarecer la historia de la implantación de este deporte en España y, en consecuencia, del lenguaje del fútbol que comenzaba a usarse con cierta frecuencia en el período en el que se publicó. Este estudio sigue en la línea de otros publicados por Nomdedeu-Rull y Torrebadella-
Flix centrados en el análisis de la historia del lenguaje del fútbol con el fin último de elaborar el DHTF. Desde el punto de vista léxico, se han podido identificar varias investigaciones parciales que han tenido como objeto de estudio el análisis historiográfico de los términos futbolísticos. Sin embargo, la bibliografía existente que se ha centrado en el análisis de dichos términos en español no es suficiente para cubrir un apartado tan importante en la historia de la lengua española como lo es el relativo al estudio diacrónico del léxico del fútbol. Esta carencia se debe tres razones: en primer lugar, al hecho de que los investigadores se han interesado más por el estudio del lenguaje del fútbol de las últimas dos décadas, que no por su análisis histórico desde los orígenes hasta hoy (Nomdedeu-Rull, 2004); en segundo lugar, se han elaborado casi más diccionarios que han tenido el fútbol ${ }^{3}$ o el deporte ${ }^{4}$ como ámbitos de interés que, en cambio, estudios de investigación que se hayan propuesto analizar el lenguaje del fútbol en los textos receptores de su terminología a lo largo de la historia; $y$, en tercer lugar, al hecho de que no se ha abordado la cuestión desde una perspectiva interdisciplinaria a partir de las aportaciones de lingüistas, historiadores del deporte y documentalistas.

El foot-ball -léase fut bol, como citaba Viada (1903, p. 481) - tuvo sus primeras adaptaciones institucionales en una obra tan ejemplar y representativa del deporte como fue el manual que nos ocupa. Las expresivas locuciones del lenguaje del fútbol (Mapelli, 2004) tienen como punto de origen las primeras crónicas y la elevación mitológica del fútbol como combate guerrero. Como trata Paniagua (2009), el lenguaje bélico ha sido desde antiguo inoculado en el fútbol y lo ha achampañado hasta nuestros días. Estas observaciones encajan perfectamente en la narrativa futbolística de las primeras obras que se ocupan de este deporte, con lo que el carácter bélico del fútbol se presenta de forma connatural a la lógica interna y externa de su juego (Torrebadella-Flix y Olivera-Betrán, 2016).

En 34 páginas (481-515) en las que Viada dedica su atención al foot-ball, se emplean 69 términos específicos del fútbol, de los cuales 39 son primeras documentaciones léxicas en español, es decir, son términos que se documentan por primera vez en este idioma. Hasta este momento, en la base de datos del DHTF se han podido identificar las 164 primeras documentaciones léxicas del fútbol en español desde 1868 hasta 1903, parte de las cuales se ha ido presentando en diferentes investigaciones (Nomdedeu-Rull, 2014; NomdedeuRull, 2015; Nomdedeu-Rull, 2017; Nomdedeu-Rull y Torrebadella-Flix, 2016). Entre estas 164 primeras do- 
cumentaciones léxicas se hallan las 39 voces que aparecen por primera vez en el Manual del Sport de Viada:

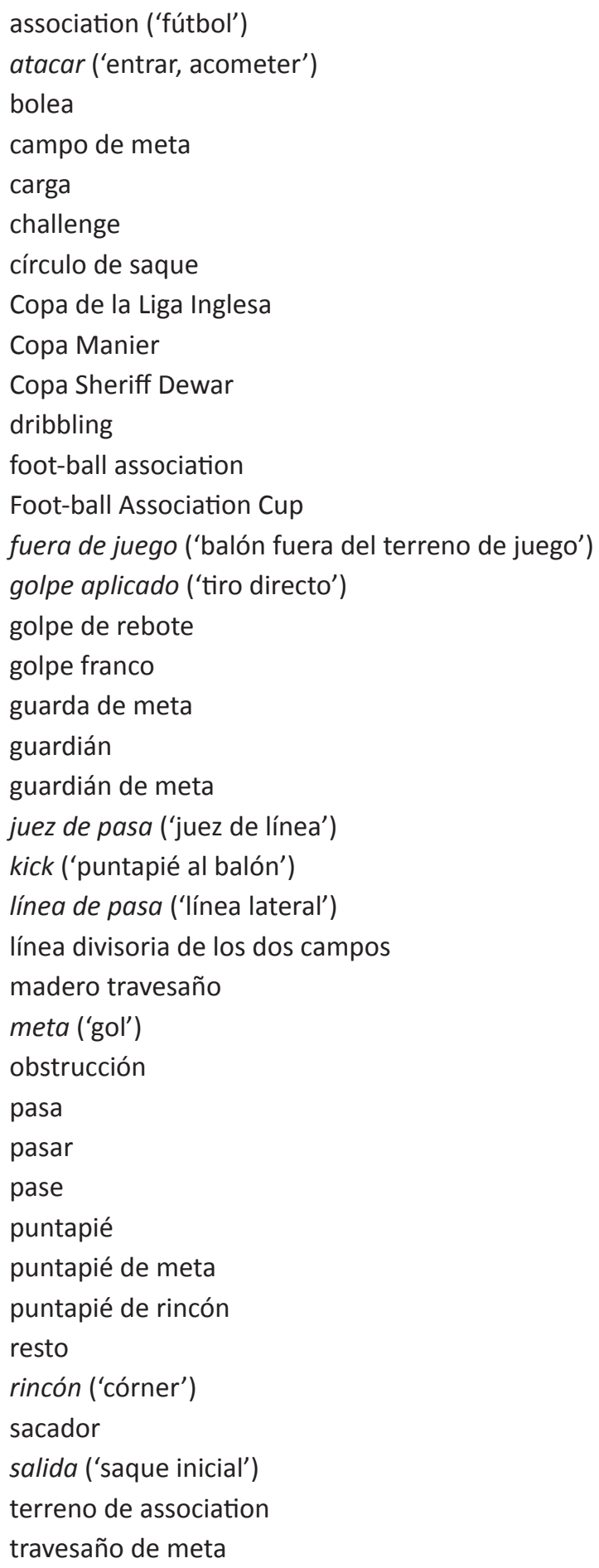

Como se observa en estos datos, el número de extranjerismos usados no era tan abrumador como se podría suponer desde un inicio. Entre los términos documentados, se observan tres que se refieren a denominaciones del juego (association, challenge, foot-ball association), cinco a demarcaciones (guarda de meta, guardián, guardían de meta, juez de pasa, sacador), nueve a zonas del campo (campo de meta, círculo de saque, línea de pasa, línea divisoria de los dos campos, madero travesaño, meta, rincón, terreno de association, travesaño de meta), 18 a acciones del juego (atacar, bolea, carga, dribbling, fuera de juego, golpe aplicado, golpe de rebote, golpe franco, kick, obstrucción, pasa, pasar, pase, puntapié, puntapié de meta, puntapié de rincón, resto, salida) y cuatro relativos a competiciones (Copa de la Liga Inglesa, Copa Manier, Copa Sheriff Dewar, Foot-ball Association Cup).

En relación con el objetivo último de este trabajo, que es aportar la documentación de términos del fútbol para la realización del DHTF, el paso siguiente lo representa el análisis de la incorporación de los términos del corpus en los diccionarios españoles, para documentar así su primera entrada en un diccionario de lengua española. A pesar de que generalmente las voces aparecen en los textos antes que en las obras lexicográficas, es posible que sean los diccionarios los introductores de determinados términos en el español.

En los párrafos anteriores, se han mostrado los 39 términos que Viada registró por primera vez en español en su Manual del Sport. Para demostrar si sus propuestas penetraron en los diccionarios españoles, en este apartado se exponen los datos relativos a las búsquedas de todos los términos realizadas en todos los diccionarios españoles. De ellos, solo tres vocablos $(7,7 \%)$ se hallan en algún diccionario de español a lo largo de la historia, lo que demuestra la escasa documentación relativa al léxico del fútbol con la que han trabajado históricamente los lexicógrafos españoles: carga y meta se incorporan en la 15. a edición del Diccionario de la lengua española de la Real Academia Española (DRAE) y dribling en el Diccionario manual e ilustrado de la lengua española (DRAEM) de la misma institución.

Asimismo, y de cara al trabajo histórico de documentación de voces para el DHTF, también es necesario buscar los términos en los textos del Corpus Diacrónico del español (CORDE) de la Real Academia Española, corpus textual desde los inicios del idioma hasta 1974 «diseñado para extraer información con la cual estudiar las palabras y sus significados, así como la gramática y sus usos a través del tiempo" y que sirve de material básico para la confección del Nuevo diccionario histórico del español de la propia Real Academia Española. El motivo de la búsqueda de estos términos en el CORDE se halla en su finalidad misma, pues, como expone la RAE en la sección de Ayuda del Banco de datos del español, «pretende ser- 
vir tanto a un investigador interesado en la existencia de una palabra o expresión o que quiera llevar a cabo un estudio gramatical, como a los lexicógrafos que con sus materiales elaboren el Diccionario histórico». Pero, además, se ha consultado el Corpus del Nuevo Diccionario Histórico del español (CNDHE). A la luz de los datos contrastados en el CORDE, no se documenta ninguna de las 39 voces del texto de Viada y en el CNDHE son siete los términos hallados (dribling, fuera de juego, kick, meta, obstrucción, pase y puntapié). Estos datos demuestran, en la línea de lo que se ha argumentado en otros estudios similares a este, que a pesar de que se trata de un corpus muy amplio de textos, en lo referente a las épocas más antiguas el CORDE presenta carencias en cuanto a la selección de textos para estudiar la historia del léxico de especialidad del español.

\section{CONCLUSIONES}

El Manual del Sport de Antonio Viada (1903) fue la primera obra técnica del deporte español que integró un capítulo dedicado al foot-ball, deporte hasta la fecha muy poco conocido en España, marcada por un regeneracionismo, modernismo y europeísmo que impregnan la obra. Con ella, Viada trató de ilustrar y propagar el deporte a partir del modelo inglés. La aportación que realizamos en este estudio es doble: por un lado, ofrecemos un análisis de contenidos de la obra más importante de la época para dar a conocer aspectos históricos, técnicos y reglamentarios de 27 deportes a los neófitos; por otro lado, exponemos las aportaciones léxicas referidas al lenguaje del fútbol. En relación con esto último, la principal aplicación de los resultados obtenidos en este estudio tiene que ver con la obtención de datos para el DHTF, que se encuentra en proceso de elaboración. La aportación progresiva de nuevas primeras documentaciones léxicas en los textos más importantes de la historia del fútbol en español contribuye a conformar la base terminológica del futuro diccionario. En último término, los datos proporcionados pueden suponer una importante aportación al Nuevo Diccionario Histórico del español de la Real Academia Española. La descripción textual del libro objeto de análisis y su contextualización en el marco histórico-deportivo de la época ofrece una información muy valiosa no solo para el conocimiento de la historia bibliográfica en español sino, en el caso que nos ocupa, para el estudio de la historia del lenguaje del fútbol en este idioma. Gracias a ello, en esta investigación podemos dar a conocer 39 primeras documentaciones léxicas del futbol en español en un texto, el Manual del Sport de Viada, fundamental para la interpretación de la historia de los términos del fútbol en español.

\section{NOTAS}

1. Las citas literales que introducimos en este artículo se reproducen tal y como aparecen en el original, de acuerdo con la norma ortográfica de la época o la grafía de la obra original.

2. Franco Sánchez (2010), erróneamente, indica que es en El Progreso. Periódico político de Jerez (1 de noviembre de 1870).

\section{BIBLIOGRAFÍA}

Agulló Albuixech, R. (2003). Diccionario Espasa de términos deportivos. Madrid: Espasa Calpe.

Aleixandre-Benavent, R., Agulló, R., Agulló, V. y Valderrama-Zurián, J. C. (2007). Terminología y lenguaje deportivo del fútbol. Cultura, Ciencia y Deporte, 2 (6), pp. 117-123.

Álvarez Santullano, L. (1903). Desde Oviedo. La vida universitaria. La Escuela Moderna, 147, pp. 447-451.
3. Polo (1996), Silveira (1996), Koch (1998), Peltzer (2007), Teruel Sáez (2007), Nomdedeu-Rull (2009), Tolares Caballero (2009).

4. Karag (1958), Agulló Albuixech (2003), Real Ramos (2003), Castañón Rodríguez (2004), Loza Olave y Castañón Rodríguez (2010), Pascual (2012).

Bibliografía (1903, 25 de junio). La Energía Eléctrica, pp. 242-243.

Castañón Rodríguez, J. (1993). El lenguaje periodístico del fútbol. Valladolid: Universidad de Valladolid.

Castañón Rodríguez, J. (2004). Diccionario terminológico del deporte. Gijón: Ediciones Trea.

Costa, J. (1901). Oligarquía y caciquismo como la forma actual de gobierno en
España: urgencia y modo de cambiarla. Madrid: Establecimiento Tipográfico de Fortanet.

Elías, J. (1901, 1 de marzo). Sport. Lo football en la present temporada a Barcelona. La llustració Llevantina, p. 1.

Elías, J. (1903, 20 de septiembre). Sports. La llustració Catalana, p. 259.

Franco Sánchez, J. L. (2010). La partida de "football" (la primera que se juega en 
España). Cuadernos de Fútbol, 6. Disponible en: http://www.cihefe.es/cuadernosdefutbol/2010/01/la-partida-de\%E2\%80\%9Cfootball\%E2\%80\%9D-laprimera-que-se-juega-en-espana/

Gamper, H. (1914). Prólogo. En Elías y Juncosa, J. Football asociación. Barcelona: R. Tobella, impresor, pp. 9-18.

García-Candau, J. (1996). Épica y lírica del fútbol. Madrid: Alianza Editorial.

J. B. (1902, 9 de febrero). De Actualidad. Remitido (Sobre foot-ball). Los Deportes, pp. 89-90.

Karag, A. (1958). Diccionario de los deportes. Barcelona: Dalmau y Jover.

Koch, W. (1998). Diccionario de fútbol. Barcelona: Paidotribo.

Kuntz, A. R. (1919, 25 de diciembre). Hace falta moverse. Madrid-Sport, pp. 3-4.

Loza Olave, E. y Castañón Rodríguez, J. (2010). Términos deportivos de origen extranjero. Logroño: Servicio de Publicaciones de la Universidad de la Rioja.

Macías, R. (1899). El problema nacional. Hechos. Causas. Remedios. Madrid: Librería General de Victoriano Suárez.

Manual del Sport (1903, 10 de junio). La Correspondencia Militar, p. 2.

Manual del Sport (1903, 22 de agosto). La Ilustración Española y Americana, p. 128.

Mapelli, G. (2004). Locuciones del lenguaje del fútbol. Atti del XXI Convegno [Associazione Ispanisti Italiani]: Salamanca 12-14 settembre 2002. Salamanca: Associazione Ispanisti Italiani, AISPI, pp. 171-182

Masferrer, N. (1903, 1 de marzo). Intimidades. Los Deportes, p. 134

Masferrer, N. (1904, 30 de marzo). A través de la prensa III. Antonio Viada. Arte y Sport, p. 9.

Masferrer, N. (1911, 23 de noviembre). Periodistas deportivos I. Antonio Viada. Mundo Deportivo, pp. 1-2.

N. M[asferrer] (1903, 15 de junio). Manual del Sport. El Cardo, p. 12.

Nomdedeu-Rull, A. (2004). Terminología del fútbol y diccionarios: elaboración de un diccionario de especialidad para el gran público. [Tesis doctoral inédita] Universitat Autònoma de
Barcelona: Barcelona. Disponible en: http://www.tdx.cat/TDX-0728105135948/

Nomdedeu-Rull, A. (2009). Diccionario del fútbol. A Coruña: Universidad da Coruña.

Nomdedeu-Rull, A. (2014). Diccionario Histórico de Términos del Fútbol (DHTF): el léxico en el primer reglamento de fútbol (1902) publicado en español. Cuadernos del Instituto Historia de la Lengua, 9, pp. 185-205.

Nomdedeu-Rull, A. (2015). Primeras documentaciones del Diccionario Histórico de Términos del Fútbol: contexto, textos fundamentales y términos (1890-1899). Estudios de Lexicografía, 1 pp. 60-73. Disponible en: http:// issuu.com/ldvp/docs/elex_febrero_ de 2015 ? $=15360805 / 11251537$

Nomdedeu-Rull, A. (2017). El corpus de textos periodísticos en el Diccionario Histórico de Términos del Fútbol (1890-1899). En Sariego López, I., Gutiérrez Cuadrado, J. y Garriga Escribano, C. (eds.) El diccionario en la encrucijada: de la sintaxis y la cultura al desafío digital. Asociación Española de Lexicografía Hispánica, pp. 665-687.

Nomdedeu-Rull, A. y Torrebadella-Flix, X. (2016). Diccionario Histórico de Términos del Fútbol (DHTF): textos fundamentales del período inicial (1890-1913). En Garriga Escribano, C. y Pérez Pascual, J. I. (eds.). Lengua de la ciencia e historiografía. Universidade da Coruña, Servizo de Publicacións, pp. 207-229.

Olivera-Betrán, J. y Torrebadella-Flix, X. (2015). Del sport al deporte. Una discusión etimológica, semántica y conceptual en la lengua castellana. Revista Internacional de Medicina y Ciencias de la Actividad Física y el Deporte, 15 (57), pp. 61-91. https://doi. org/10.15366/rimcafd2015.57.005

Paniagua, P. (2009). Cultura y guerra del fútbol: Análisis del mensaje informativo. Barcelona: Universitat Oberta de Catalunya.

Paniagua, P. (2010). Información deportiva, la especialización más extendida. En Camacho Markina, I. (coord.). La especialización en el periodismo. Formarse para informar. Sevilla: Comunicación Social ediciones y publicaciones, pp. 182-196
Pascual, J. A. (2012). Sobre el léxico deportivo. A propósito de un corpus modular para el NDHE. En Lakarra, J. A., Gorrochategui, J. y Urgell, B. (coord.). Il Congreso de la Cátedra Luis Michelena. Bilbao: Servicio Editorial de la Universidad del País Vasco, pp. 1-22.

Peltzer, F. (2007). Léxico del fútbol. Buenos Aires: Academia Argentina de Letras.

Polo, A. (1996). El diccionario de fútbol. Madrid: Ediciones Altea.

Polo del Barrio, J. (1993). El fútbol en Madrid: de actividad lúdica a espectáculo de masas (1898-1945). [Tesis doctoral inédita]. Universidad Complutense de Madrid: Madrid. Disponible en: https://www.tdx.cat/handle/10803/512071

Pujadas i Martí, X. y Santacana i Torres, C. (2012). Prensa, deporte y cultura de masas. El papel del periodismo especializado en la expansión social del deporte en Cataluña hasta la guerra civil (1890-1936), Historia y Comunicación Social, 17, pp. 141-157. Disponible en: http://revistas.ucm.es/ index.php/HICS/article/view/40603

Real Academia Española (1979). Diccionario de la lengua española (15.a ed.). Madrid: Espasa-Calpe.

Real Academia Española (1984). Diccionario manual e ilustrado de la lengua española. Madrid: Espasa-Calpe.

Real Academia Española. Corpus diacrónico del español (CORDE). [En línea]. Disponible en: http://www.rae.es/ recursos/banco-de-datos/corde

Real Academia Española. Corpus del nuevo diccionario histórico del español (CNDHE). [En línea]. Disponible en: http://web.frl.es/CNDHE/view/inicioExterno.view

Real Ramos, E. (2003). Diccionario Espasa de términos deportivos. Madrid: Espasa Calpe.

Reparaz, F. (1919, 15 de diciembre). Olimpismo. Heraldo Deportivo, pp. 472-473.

Serra, A. (1903, 17 de enero). Notas de Sport. La Vanguardia, p. 7

Silveira, D. (1996). Diccionario de términos futboleros. En Pereira, J. M., Pelé estuvo aquí. Barcelona: Montesinos, pp. 133-182. 
Teruel Sáez, A. (2007). Vocabulario de fútbol. Gijón: Trea.

Tolares Caballero, G. (2009). El lenguaje del futbol. Prontuario de términos y frases características en México. México: Editorial Trillas.

Torrebadella-Flix, X. (2011). Repertorio bibliográfico inédito de la educación física y el deporte en España (18001939). Madrid: Fundación Universitaria Española.

Torrebadella-Flix, X. (2012). Orígenes de fútbol en Barcelona (1892-1903). RlCYDE. Revista Internacional de Ciencias del Deporte, 8 (27), pp. 80-102. https:// doi.org/10.5232/ricyde2012.02706

Torrebadella-Flix, X. (2014). Regeneracionismo e impacto de la crisis de 1898 en la educación física y el deporte español. Arbor, 190 (769), a173. https:// doi.org/10.3989/arbor.2014.769n5012

Torrebadella-Flix, X. y Nomdedeu-Rull, A. (2013). Foot-ball, futbol, balompié... Los inicios de la adaptación del vocabulario deportivo de origen anglosajón. RICYDE. Revista Internacional de Ciencias del Deporte, 31, pp. 5-22. https:// doi.org/10.5232/ricyde2013.03101

Torrebadella-Flix, X. y Nomdedeu-Rull, A. (2014). Bibliographic Repertoire of Football in Spain (1900-1936). 121 works to interpret the social impact of football in contemporary history. Apunts d'Educació Física i Esport, 115, pp. 7-32.
Torrebadella-Flix X. y Nomdedeu-Rull, A. (2015). Los primeros libros de fútbol publicados en España (19001919). Revista General de Información y Documentación, 25 (1), pp. 113-139. https://doi.org/10.5209/ rev_RGID.2015.v25.n1.48985

Torrebadella-Flix, X. y Nomdedeu-Rull, A. (2016). La popularización del fútbol en España. Análisis del fenómeno a través de la literatura especializada del fútbol (1920-1936). Revista General de Información y Documentación, 26 (1), pp. 119-146. https:// doi.org/10.5209/rev_RGID.2016.v26. n1.53040

Torrebadella-Flix, X. y Olivera-Betrán, J. (2012). Las cien obras clave del repertorio bibliográfico español de la educación física y el deporte en su proceso de legitimación e institucionalización (1807-1938). Revista General de Información y Documentación, 22, pp. 119-168. https://doi.org/10.5209/ rev_RGID.2012.v22.39669

Torrebadella-Flix X. y Olivera-Betrán, J. (2013). The Birth of the Sports Press in Spain within the Regenerationist Context of the Late Nineteenth Century. The International Journal of the History of Sport, 30 (18), pp. 21642196. https://doi.org/10.1080/0952 3367.2013.854775

Torrebadella-Flix, X. y Olivera-Betrán, J. (2016). Institucionalización del fútbol en el ejército español (1919-1920). Orígenes del patrioterismo futbolís- tico nacional. El Futuro del Pasado. Revista electrónica de historia, 7, pp. 497-532. https://doi.org/10.14516/ fdp.2016.007.001.018

Torrebadella-Flix, X., Olivera-Beltrán, J. y Bou, M. M. (2015). Origin and Institutionalisation of Sports and Gymnastics Associations in Nineteenth-Century Spain (1822-1900). Apunts: Educació Física i Esports, 119, pp. 7-54.

Torrebadella-Flix, X., Olivera-Betrán, J. y Bou, M. (2017). The origins of football in Spain. From the first press appearance to the constitution of the first clubs (1868-1903). The International Journal of the History of Sport, 34 (7-8), pp. 471-497. https://doi.or g/10.1080/09523367.2017.1365707

Turuzeta, J. (2012). El Athletic Club. Origen de una leyenda o cuando el león era un cachorro. San Sebastián: Txertoa.

Vázquez Montalbán, M., Mercé Varela, A. e Ibarz Melet, J. (1972). 100 años de deporte: del esfuerzo individual al espectáculo de masas. Barcelona: Difusora Internacional.

Viada, A. (1902, 27 de abril). Sobre el vocabulario deportivo III, Los Deportes, pp. 243-245.

Viada, A. (1903). Manual del Sport. Madrid: Librería Internacional de Romo.

Viada, A. (1903, 15 de junio). Lo que es sport. El Cardo, pp. 12-13.

Zulueta, J. (1903, 22 de septiembre). Culto a la acción. El progreso de Asturias, pp. 1-2. 